\title{
Public Spaces, spaces of public domain: Icons of a contemporary simulacrum?
}

\author{
Manoel Rodrigues Alves [0000-0002-6935-0477], University of São Paulo, \\ Institute of Architecture and Urbanism, São Carlos, Brazil.mra@sc.usp.br
}

\begin{abstract}
The contemporary city is a result of plural connections between the historical matrix and the effects of global policies. Immersed in a flux of multiple contents, it seems to respond to an era of transition in which the sense of belonging to an urban space is profoundly tensioned by transformations in the cultural, social, technological and political dimensions of public space. On the one hand, contemporary urban territorialities bring new possibilities to issues related to urban morphology and fabric that are still mainly culturally determined; on the other, contemporary thinking confronts itself with the tendency of a global scenario where public life and contemporary culture are related to consumption and capital circulation. Although relations of belonging and attachment to the urban space may persist, the flow of global conditions seems to have an impact upon collective experience in the urban territory and in the production of public space. These are transformations that may lead not only to the instrumentalization of space but also to the reduction of its 'public' value. In the contemporary city we observe particular processes of functional and economic spatializations of the urban where public spaces are not conceived as spaces of a public realm. Noting that the intersection between past/present time-cultural flows should go beyond the (re)production of any new global paradigm of thematic urban configurations, we argue that the theoretical constructs of the contemporary public space, or spaces of public domain, must be representative not of a thematic 'everywhere-nowhere' urban environment, but rather of a public life urbanity, one built upon awareness and around political and civic issues.
\end{abstract}

Keywords - In-between space, contemporary city, spaces of public domain, technology 


\section{INTRODUCTION}

This chapter intends to foster the understanding of the contemporary city and to question processes and transformations of public open spaces (hereon just public spaces). Both, the city and the public space seem to respond to an era of transition in which the sense of belonging to the urban space is profoundly tensioned by transformations in the political, social, economic, cultural, technological and environmental dimensions. The feeling of belonging to an urban space, conditioned by the flow of local and global conditions, persists and may have an impact not only upon collective experiences and personal attachment but also on the reconfiguration of contemporary public spaces.

Critical approaches to today's urban public spaces question the "urban", its interpretations and forms of appropriations (space and territory/spatialities and territorialities). We may argue that transversalities and tangencies to the contemporary public space promote urban practices beyond its 'regular' limits, combining itself into new hybrid patterns'. Still, in a context of increasingly flexible and multi-layered public spaces, what kind of publicness can be produced/recognized? What collective practices and discourses are being (re)produced as mechanisms for the signification of contemporary public spaces? What is the impact of technological transformations in the public space? Recent social and technological transformations reinforce the instrumentalization of public spaces and the reduction of their 'public' value. Consequently, it is not uncommon to observe a public space that, due to the loss of symbolic value, is no longer the physical counterpart of a civil society understood as a subject of the city. A public space where the disruption of its boundaries and power arrangements point to the dissolution of meanings that affect the collective public experience; where we observe the impoverishment of social representations and the retraction of collective forms of life - for Augé, established "blind spots" (Augé, 1994), spatial conditions that promote, in relation to the city, citizens' alienation.

\section{WHAT ABOUT? (I)}

In a context where liminalities, tensions and boundaries become blurred, and new tangencies may define new 'places', the relationship between constructed public spaces (or spaces of public domain ${ }^{2}$ ) - permanent or temporary, formal or informal - is vital for the possibility of new urban fabrics and conceptual constructions.

\footnotetext{
' Hybrid patterns, hybridization processes as a matter to be thought not only by means of their production but also in terms of their assimilation and continuous development in the debate of the public (and spatial) spheres of the urban environment.

${ }^{2}$ Nowadays the classical notion of public and private space is obsolete and does not answer the complexity and publicness arrangements of the contemporary urban space appropriately. There are forms of contemporary physical public spaces that, in fact, may not even be so public. For instance, private spaces that may act like public spaces: spaces of public domain that act as public spaces (like shopping centers or 'pops', privately owned public spaces). Although the distinction between public spaces and spaces of public domain will not be developed in this chapter, it is necessary to understand that otherness and diversity, in a public rather than an artificial way, are essential constitutive elements to public spaces.
} 
We argue that we should focus on the (re)signification of new multi-referential "in-between" spaces of public domain, diverse and hybrid due to their public condition. "In-between", between two clear or accepted stages or states, having the qualities of two things, therefore difficult to describe or know exactly. "In-between" public spaces that break boundaries, deal with porosities, intermingle dimensions and conceptions demand studies that interrogates contemporary spatialities and territorialities. "In-between" public spaces that are not just the setting for occasional programmed collective political actions that conform the urban space, but rather for otherness.

The contemporary city, in its new forms of cultural enunciation, considering urban fabrics and territorialities, bring about new questions to the urban environment, thus also promoting new contiguous and ambiguous symbolic interpretations, demanding investigation of the cultural spatiality of the public realm of the urban space (Alves, 2006). It is a matter of observing not only emerging urban forms and their culturally implemented referential universes, but also intermingled relations between public space and public sphere, urban place and public spatiality, urban space and culture image, urbanalization ${ }^{3}$ and city consumption. Challenging the tensions between domains, legalities and socio-spatial practices related to the public space and spaces of public domain - beyond the models and concepts instituted in Architecture, Urbanism and Social Sciences -, this questioning may open up new possible interpretations of the relations between urban morphologies and cultural constructions.

In the complex pathways of contemporary culture, the topology of place construction is determined by a new socio-technical multi-referential scenario of multiple utopias, of a mediatic society in which culture is associated to consumption. Its practices are associated more to a mediation of capital circulation than to the social milieu. In this context, the public scope of the contemporary urban space must deal with a particular new social-technical capital market determined by a hegemonic global economic model, as well as by the impact of information technology upon societies.

New forms of cultural expression and social communication open unexplored fields of investigation and practice regarding urban spatial structures. Yet, at the same time, they threaten public life and the idea of city ignoring the urban space as a social product, representative of historical values and endowed with local symbolic culture. In this scenario, the analysis of concrete spatial situations related to a public space of multiple dimensions demands the observation of questions related to its context and product, such as: the strategic absorption of the textuality of the localism; the cultural, functional and economic specialization of urban processes; new morphological patterns that may lead to segregated urban environments; or thematic urban landscapes that deal with the urban space as a commodity. Besides

\footnotetext{
${ }^{3}$ The urbanalization, concept proposed by Francesc Muñoz based on Pardo's notion of banal, which reveals a simplification of the city by means of a process of standardization of the urban space, mostly based on the homogenization of its singularities, in which urban diversity is submitted to a common global order. (Muñoz, 2008)
} 
all these questions, another one remains: the essence of public spaces as locus of conflict, diversity, otherness and the possibility of resistance as its essential element. In a context where more and more spatial patterns of urban fabrics are submitted to a global homogeneous process, contemporary thinking confronts itself with the totalizing tendency of capital upon culture. In the textualities of the multiple dimensions of today's city, a city whose paradigms have been destabilized by undetermined and diffuse territorialities, the classical conception of public space and the ways to conceive the distinction between public and private territories must be reframed. It is in this framework that the manipulation of heterogeneous and complex elements, be they unique or not (urban typologies, 'new' urban planning rules or theoretical constructions), should be considered in the analysis of urban models in order to avoid the prevalence of processes representative of territorialization and de-territorialization phenomena (in relation to their spaces, sceneries and actors), products of the relationship between culture, capital and global economy.

As a matter of fact, the manipulation of social, cultural, political and technological transformations, also by means of image combination and re-composition, validate a particular urban model, one that simulates urban environments that disregard most of their physical or social references - to a certain extent, an example of Sorkin's 'ageographical cities' (Sorkin, 1997). This is also a model that promotes cities that do not necessarily represent singular social worlds, but that answer a pre-established imagery. In the city of discursive stratifications or in the city of another genealogical 'topos' - where, in both cases, concepts, forms and spaces mark events -, it is necessary to focus on the socio-cultural dimensions of the emerging contemporary ways of urbanity - socio-spatial practices that correlate their public dimensions to their transformation processes and permanencies, their structure elements and their strength lines.

\section{WHAT ABOUT? (II)}

In this scenario, to what extent do the so-called innovative landscapes of the global age appropriately respond to new forms of enunciation of the spatiality of the contemporary public space? To what extent is the spatiality of new urban fabrics submitted to a homogeneous cultural and economic context that may promote the logic of social and spatial segregation of privatized spaces?

Any attempt to deal with the notion of public space today must understand the dichotomy between a plurality of social practices and several faces of the transformation of the notion of the city, encompassing both a unifying global meaning and the appreciation of differences in meaning. The notion of the city as a public good, a place of conviviality and conflict - conflict in the sense of diversity and debate, of otherness -, is nowadays being questioned by another idea of urbanity. One that does not take into consideration that conflict is part of the essence, one of the basic 
elements, of public space, of the constitution or destitution dimensions of its public spheres, of the public and private dimensions that constitute the classic grammar of the urban life.

In a shuffled grammar based on a strategy of social control and reproduction of an established order, where the sense of history has been mostly reduced to an appearance imitation/simulation game, we experience a different sense of urbanity: from the modern form and function to a post-modern fictional spectacle. This grammar answers mainly to sectors of the market, fashionable formalisms, aesthetical experimentations and media codes instead of to the complex articulation of daily urban life, often transferring civic activities to spaces of private domain or promoting new spatialities of global pre-determined imagery.

We observe the transformation of the public urban landscape into a product, an object of new tastes for consumption, legitimizing a new sense of urbanity that, under the impact of neo liberal policies and global models of urban interventions, promote the deflation of the public urban sphere (Alves, 20I4). In the contemporary urban spectacle, the public space, attached to the system of production and consumption of goods, is related to the production of a space-landscape of saturated images - for instance, Vrijthof Square in Maastricht (see Fig. I). In it, the goods, in seductive image forms, become the constitutive principle both of the organization and of the relations of social practices. In the superabundance of the 'post-city' we face, on the one hand, the city as a spectacle, not just a mere display, the place and the way of receiving the aesthetical social relationships of contemporary culture; on the other, the aesthetization and spectacularization phenomena become powerful mechanisms of symbolic control of the production of the urban landscape and its spatiality. As a consequence, it also becomes an urbanity in many cases related to the transformation of the private/ public relation and the promotion of a particular spatiality of social segregation.
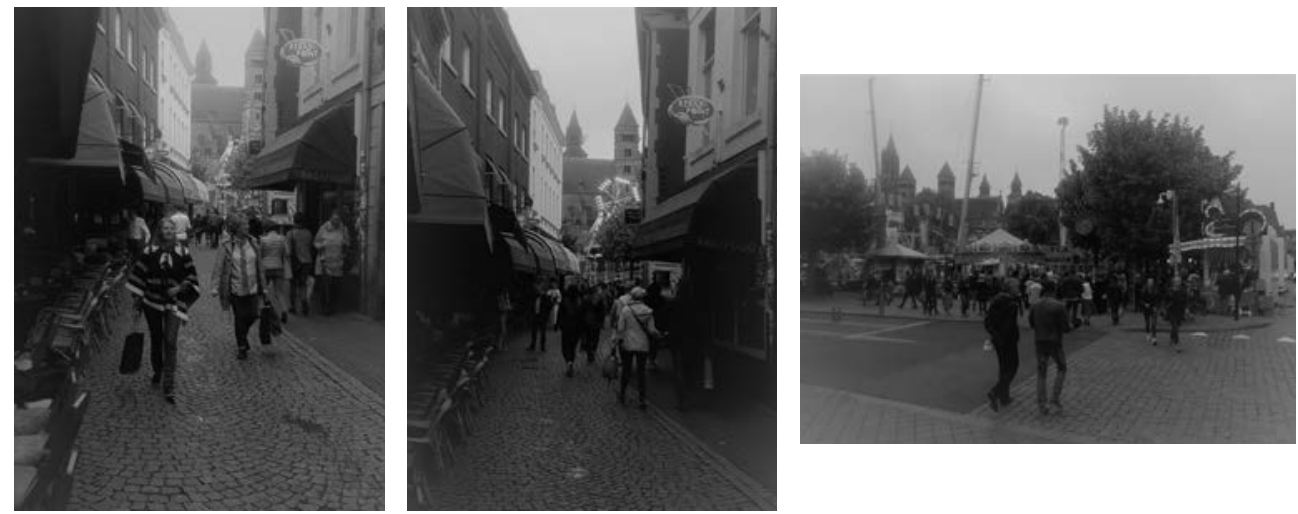

Fig. I: Maastricht, 2018. Scenes of public space: a thematic object of consumption? Photos by the author. 
If it is true that cities and public spaces are composed of urban structures determined by conflicts of different natures, objects and actors, it is also true that the stage and dimensions of these constitutive elements have been transformed in the last few decades - for social, economic, political and technological reasons. Conflict and consensus are two fundamental aspects (some will say configurations) of the distinct conceptions of public space and public sphere. They govern the classical elements of urban life, presenting today an intermingled grammar in which the real and virtual dimensions are jumbled in a blurred zone that jeopardizes the independent existence of any of these constitutive spheres of public spaces. Consensuses are articulated in a kind of artificial form, more or less fabricated, but not less efficient, one that frames urban conceptions, images, interventions and proposals in a multiple-scale public space.

Therefore, what we observe is no longer an ordinary public space transformation, but, in fact, a highly sophisticated urban model that continuously interchanges brand and commodity, commodity and space. In this context, the experience of the visual, in many ways supported by technology, consolidates itself as a mediating element between the landscape and the geography, between the city and the territory, between the individual and the public space, becoming central to the reproduction of the urban space. In the global age scenario, 'avant-garde' public spaces are mostly related to a banal type of consumption environment, where practices, knowledge and identity are submitted to a homogeneous cultural and economic context. To a certain extent, these so-called 'avant-garde' public spaces do not necessarily articulate with each other or with the urban landscape, mostly promoting an urban fabric of social and spatial thematic cities within the real city. This is an environment that reduces the sense of context and the relations of everyday life with the appearance - immaterial condition -, where the urban public space loses its social meaning allowing for a de-territorialized urban form. These cities are not cultural artefacts to be experienced, but rather, as a result of consumerism and commercialization, fake objects of space-consumption of an aesthetic empty form.

\section{WHAT ABOUT? (III)}

As a matter of fact, an emergent city operates in a differentiated social-cultural context. This city, on the one hand, encompasses an intrinsic relation with the urban culture and with an imagery submitted to significant processes of social and technological transformations, and, on the other, requires the revision of concepts and action plans regarding its spatiality (both physical and social). In this contemporary city the urban space is evidenced in many ways, either mapping out and questioning the emergence and transformation of new conflictive processes (around the classic axis of the structuration and appropriation of the public space) or in contemporary forms that can or cannot dislocate and/or substitute old demands.

In the contemporary urban space, heterogeneity, which is intrinsic and necessary, is at the same time fostered and crushed by the overlapping of a collage of social 
assemblages and urban forms (of coexistence), only possible in a society of mass production where a kind of 'inflation' of products and information reigns. In our contemporary society 4 spatialities create new proximities and explicit distinct material, political, economic and ethnic landscapes, according to a container logic: traditional typological elements, as streets, squares, public and institutional spaces -, are transformed into containers-objects, thematically reduced to a set of the urban functions of a controlled space 5 , a space of idleness, consensus and consumption characterized by models and similar standards of intervention in the production of an urban environment, particularly public spaces, to be visited intensively in part time (Muñoz, 2008). This is an urban space that produces a-territorial landscapes characterized by the economic and functional specialization of the territory - in every place, landscapes of nowhere, related not only to the materiality of space, but also to its permanency, ephemerality and de-territorialization (temporal substractum). In fact, the contemporary public space materializes itself in a polarized city that loses identity and meaning, becoming more and more difficult to be noticed as public object. These are cities where urban networks and / or urban structures are not conceived as a public realm that results from the overlap of historical times and social, cultural, economic and political processes. What we see are the so called 'place-specifics' of homogeneous urban landscapes which offer lifestyle choices and amenities that promote "new" standards of behaviour and social appropriation of urban public spaces. If that is so, to what extent can we say that public and private spatialities, appropriations of places, formal references of identities and sociospatial practices are still to be inquired and interpreted as a phenomenology of diversity, a diversity which, while recognizing influences, reveals differences, that allows for otherness.

\section{ALMOST FINAL OBSERVATIONS (I)}

Public spaces are nowadays mostly scenographic spaces of visual consumerism, fragments of urban displays reduced to the surface of urban appearances composed by isolated pictures, mostly vectors of privatized fortresses ruled by control, exclusion and claustrophilia. Public spaces that set aside the urban space, creating a fictional city ruled by the interiorization of functions of the 'old city' - a city built by simulacra of public spaces that disregards the importance of the place. A city where identity disputes and appropriations of the past are no longer the counterpoint between the constructed and/or official memory and other versions of the social memory.

In this 'ageographic' city of huge containers, of gentrifications brought about by the homogeneous urban renewal proposals of private capital, we observe - independently

\footnotetext{
${ }^{4}$ Augè characterizes the contemporary society as the society of super modernity, defined by the factual and spatial superabundance and the individualization of the references (Augè, 1994).

${ }^{5}$ Containers, accordingly, to Solà-Morales' definition, are understood as elements of capital accumulation and reproduction: economic, cultural, touristic or social capital (Muñoz, 2008).
} 
of the technological impact - public spaces of temporary occupation and anonymous confluence, flexible space-time contexts designed for the client, not for the citizen. Failing to consider this aspect will lead to further human alienation in a time of estrangement from the world, an alienation based on the individual experience of dislocation and detachment, one where a common pattern of public space easily transforms the urban space into an empty form. When it loses its social meaning, when displacement takes place, the public space loses its sense of belonging.

Although the urban space is both a product and the producer of the dynamics that governs its time, the experience of urban life and the relation of belonging to the urban space differ in the midst of a set of transformations that affect several dimensions - from the right to appropriate urban space to the appropriation of hybrid spaces (according to the understanding presented above in this chapter). Our shuffled reality transforms any act concerning the public space and the contemporary city into an extensive series of successes and failures that peacefully coexist along with conceptual and operational intentions to govern complexity, if not for any other reason because hybridization processes blur the boundaries between legal and illegal, formal and informal, modern and contemporary, citizens and foreigners, homeless and no-right population to a point where it is almost impossible to determine the dimensions of grey areas, to distinguish subjects and stakeholders, nature and culture, centres and peripheries, media-dimensions and native cultures, public and private spaces - publicized or privatized. As an enigma, the contemporary emphasis has accelerated displacements of the representation of things in the world and promotes a recurrent flow of instabilities. In contemporary times, the territories of representations replicate themselves in contingency accidents, contaminated and hybrid, relative and syncretic. In contemporary times, things change - instantaneously, in immediate terms - without necessarily operating a synthesis of thought (theoretical) or realization (practice) of some outcome.

\section{ALMOST FINAL OBSERVATIONS (II)}

It is in this context that the urban space, a space of representation of human relations, chaotic traces of confluence of pluralities of cultures and ways of life, remains the result of singular forms of the relationship between man and his physical space that govern and participate in events. In a world in which the contemporary built environment is representative of a new universal paradigm, an 'everywherenowhere' model of production of the contemporary urban space ${ }^{6}$; in which spatial

\footnotetext{
${ }^{6} \mathrm{~A}$ model that, as a result of a pre-established imagery, looks for legitimacy on the superimposition of a global and modern matrix over the archaic and uneven city. According to Boyer (1996), the urban representational model of the contemporary city envisages the city as a spectacle that corresponds to the global capital in constant flux. The image of the city of the spectacle, without territorial and physical specificities, represents an urbanity and urbanization processes more and more privatized. We observe today urban interventions representative of gentrification processes, which generate social expelling and exclusion and reduce the complexity and heterogeneity of the urban environment to an aseptic vernacular landscape of civility. The city of the spectacle is the transformed city, as much as possible, in goods; a city where the cultural capital has an important role in the definition of its physical and social transformations.
} 
conformations and socio-spatial phenomena, conditioned by the dynamics of advanced financial capital, structure and promote, in the use and appropriation of space, the dissolution of stable relations with the physical and cultural geography of space itself; where the aspects of entrepreneurship of the city emerge with special resonance, it is important to (re)-learn to capture social urban forms.

Operating in a different sociocultural context, the intersection between past/ present time-cultural flows should go far beyond the (re)production of a new global paradigm of thematic urban configurations in the production of a city that responds to an era of transition (as mentioned above); a city of unprecedented forms of enunciation, of a contemporaneity conformed by economic globalization and the planetarization of processes that conform daily life; a city where micro-geographies of a public space of new uses and appropriations are determined, at least to a certain extent, more by the needs of a highly commodified world than by human needs in time and space.

In this context, what are the conditions that conform public space? Are we living in a condition of simulacrum of public spaces as part of the social construction of urban form? The public space has been transformed in the contemporaneity, not only accounting for the fact that new technological conditions of communication and mobility are increasingly permeating space through physical deployment (Internet of Things devices, for example) but also that urban transformations are characterized by a dilemma of complex uncertainty. Whatever the level of uncertainty, it is fundamental to recognize the change from the key "city-work-politics" to another one, according to a new diagram of an entrepreneurial nature: "city-management-business". Crary (20I4), in his book '24/7 - Late Capitalism and the Ends of Sleep" argues that productive processes and labour relations were completely restructured in a new logic of flexibility. What was conventionally called 24/7 - 24 hours for seven days a week - was made possible by processes of a new global infrastructure for work and consumption - for instance, an automatic self-service Pizza Place (see Fig. 2). The expression 24/7, beyond the notion of frivolity, disallows any overlapping of meanings of rhythm and periodicity, presupposes an arbitrary and inflexible system of a weeklong operation, seemingly emptied of relations and the unfolding of the cumulative experiences of human life.

A 24/7 environment appears to be a social world of flexibility, speed and efficiency, but in reality, it is a machine-operated model, an antisocial suspension of life that does not reveal the human cost that underpins its effectiveness and its functioning. In the restless acceleration of a time that does not remain the same, we observe, simultaneously, a demand for change and a search for the anonymous, a demand for updating and a search for identification.

Under these conditions, the 24/7 time, marked by indifference, is the reminder of a pre-modernity that has not been completely overcome. The ambition of models 


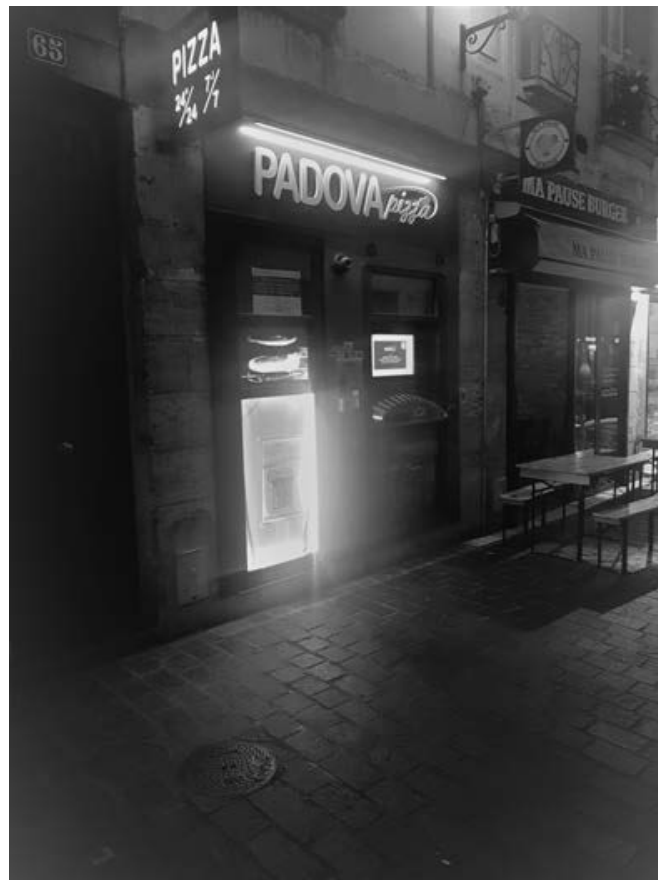

Fig. 2: Tours, 2018. 24/7 Self-service automatic Pizza Place. Photo by the author

such as these refers to a new set of panoptic practices, creating control conditions according to full visibility. One of the most widespread clichés in the technological discussion, as Crary (2014) puts it, is the occurrence of a historical shift in a very short interval of time when technologies have superseded a whole set of older cultural forms. However, understanding global contemporaneity as a new technological age results in the apparent conclusion that the context hitherto developed would be unavoidable, attributing large-scale economic changes to small phenomena of everyday life. In this sense, the illusion that there is a unified and lasting link between the many constituent elements of contemporary experience is perpetuated, in such a way that we would move towards an apparent level of technological and intellectual competence never seen before. The production of urban space is linked to such transformations.

\section{FINAL OBSERVATIONS}

"When the exclusions governing the constitution of political public space are naturalized and contests erased by declaring particular forms of space inherently, eternally, or self-evident public, public space is appropriated" (Deutsche, 1997: 122). We live in an era of digital transformations, for good or for bad. Beginning after the Second World War, the mainstream narrative has claimed that digital technologies would enhance positive transformations related to, among others, global knowledge, transparency, inclusion 
and quality of life. More recently, a critique has been provided of this evaluation pondering questions of control, surveillance, loss of privacy as well as of belonging. Ironically, people start to fear what is different, what is unequal, and find themselves more and more inmates of their own social ghettos.

Our current reality is determined by a situation of incremental technological changes that question the possibility of urban stability in a global hyper-mediatic society of the post-industrial era. It is in this mumbo-jumbo that the production of contemporary public spaces occurs, one where the loss of reality in urban life is the other side of the coin in a city that is unable to show anything but an image (devoid of stimulus and knowledge), and vice-versa.

Public spaces are places where collective or individual rights should be affirmed, exercised or confronted socially. Public space depends on social tolerance, diversity, conflict, that is to say, on the availability of the coexistence of diversity, of the differentiated. Public spaces are established through concrete forms and actions, anarchic, despotic or democratic, utilitarian or philanthropic, temporal or permanent, through physical forms that demand the understanding of the meaning and nature of their physical configuration. Confrontation does not reduce, but actually affirms relationships and interactions. In our times, "in-between" spaces of manifestation of public life, space-time structures that make possible the realization of relational life, propose a critical reflection on the meaning of between, otherness, mediation, certainty in the public space, a place between places. However, the contemporary public space, configured by barriers and limits, seems to be prepared for consensus, not for otherness. Therefore, in these contemporary times, how may the meaning and performance of publicness differ in distinct "in-between" city patterns of public spaces?

As Deutsche (1997) claims, public space is fundamentally a political space, a democratic space whose protagonist is an abstract entity that we call citizen. It is necessary to put an emphasis on open and iterative processes of co-creating public spaces. "In-between" ambiguous spaces of invention, producers of knowledge, hackers of new spatialities that may offer new connections with the city and today's culture.

Any investigation into the configuration of these "in-between" relationships of contemporary spatialities must observe narratives of multiple natures to better understand public space scenarios of a heterotopic society where: we observe a dislocation from the model of industrial city to diffuse and undetermined spatial patterns; the phenomena of demographic explosion and customs implosion entail new patterns of urban morphology and force us to (re)think the city in light of today's multifaceted reality; there is not only the chronological or linear sequencing, replacing the synchronic space-time of the mnemonic landscape; we observe a non-serial asynchronous time of "pass-see-pass" that mirrors the images of sporadic appearances and forms a landscape of "pass-time" images. In this scenario, cultural, 
social, political and economic issues, as well the impact of information technology, are important elements to be considered. To be considered, not necessarily to be accepted, thus making it possible to avoid the development of a techno-aesthetic view of alienation from the context.

Public places must be based on social plurality (not a fake one), considering not only permanencies but also the local identity, instead of thematic urban landscapes; social cohesion and dynamic urbanity, instead of global 'urbanilization' processes of functional and economic spatialization. New territorialities of public domains substantiated and built up on the collective memory of a multi-referential social plurality are central to enabling multireferential public spaces and their distinct representations, in opposition to the obscurity and devaluation of a simulacrum of a collective memory of frozen fragments, valued by the consensus of a thematic official history - as we increasingly see in an urban context of pre-defined imagery. We believe that this is a possible way to long for a city of public spaces that are not transformed into cultural technocratic spaces and consumer-oriented products of a supposedly global technological "avant-garde" of mere commercial (re)production.

\section{REFERENCES}

Alves, M. R. (2006). Público y privado: cultura, consumo y la espacialidad de la ciudad contempránea. Polis 9, 42-53.

Alves, M. R. (2014). Transformações culturais e contradições Urbanas do Espaço Público Contemporâneo. Processos Extremos na Constituição da Cidade, vol I I, 470-497.

Augè, M. (1994). Não-Lugares. Uma introdução a uma antropologia da supermodernidade. Campinas: Papirus Editora.

Aurigi, A. (2013). Reflections towards an agenda for urban-designing the digital city. Urban Design International 18, vol 2, I3I-I44.

Boyer, M. C. (1996). City of collective memory: its historical imagery and architecture entertainments. Cambridge: MIT Press.

Brenner, N. (2013). Implosions/explosions: towards a study of planetary urbanization. Cambridge: Harvard University Press.

Brighenti, A. (2010). The Publicness of Public Space: On the Public Domain. Quaderni del Dipartimento di Sociologia e Ricerca Sociale; 49. Retrieved from: http://eprints.biblio.unitn.it/ /844/

Crary, J. (2014). Late capitalism and the end of sleep. London: Verso.

Cuff, D. (2003). Immanent domain: pervasive computing and the public realm. Journal of Architectural Education 57 , vol I, 43-49.

Delgado, M. (2008). El animal público: hacia una antropología de los espacios urbanos. Barcelona: Editorial Anagrama.

Deutsche, R. (1997). Evictions. Art and spatial politics. Cambridge: MIT Press.

Han, B.-C. (2015). The Transparency Society. Stanford: Stanford University Press.

Han, B.-C. (2015a). The Burnout Society. Stanford: Stanford University Press.

Hespanhol, L., \& Tomitsch, M. (20I5). Strategies for intuitive interaction in public urban spaces. Interacting with Computers 3, vol I, 3II-326. 
Innerarity, D. (2006). El nuevo espacio público. Madrid: Espasa.

Lefebvre, H. (20I4). Dissolving city, planetary metamorphosis. Environment and Planning. D: Society and Space 32 (2), 203-205.

Lydon, M., Bartman, D., Woudstra, R., \& Khawazard, A. (2012). Tactical urbanism. Short-term action, long-term change. Miame; New York: The Street Plans Collaborative.

Lydon, M., Bartman, D., Woudstra, R., Garcia, T., \& Preston, R. (20I2). Tactical urbanism. Short-term action, long-term change 2. Miame; New York: The Street Plans Collaborative.

McCullough, M. (2005). Digital Ground. Cambridge: The MIT Press.

Morin, E. (2005). Introducción al pensamiento complejo. Barcelona: Editorial Gedisa.

Muñoz, F. (2008). Urbanalización. Paisajes comunes, lugares globales. Barcelona: Gustavo Gili.

Sloterdijk, P. (2003-2008). Esferas I; Esferas II; Esferas III (Trilogia). Madrid: Ediciones Siruela.

Sloterdijk, P. (2009). Haz que cambiar tu vida. Madrid: Ediciones Siruela.

Smith, N. (2008). Uneven development: nature, capital and the production of space. Athens: University of Georgia Press.

Solà-Morales, I. (2002). Territorios. Barcelona: Gustavo Gili.

Sorkin, M. (1997). Variations on a theme park. New York: Hill and Wang.

Zukin, S. (2002). The Culture of Cities. Oxford: Blackwell Publishing. 